\title{
IMPLIKASI PENERAPAN CUSTOMER RELATIONSHIP MARKETING DAN DIGITAL MARKETING TERHADAP KEPUASAN KONSUMEN PADA PT GAPURA ANGKASA JOUMPA DENPASAR
}

\section{NI PUTU MIRA DWI ASTUTI ${ }^{1)}$,I KOMANG MAHAYANA PUTRA ${ }^{2)}$, KASIANI $^{3)}$, COKORDA GEDE PUTRA YUDISTIRA ${ }^{4)}$, I MADE WIDIANTARA ${ }^{5)}$}

\author{
Jurusan Administrasi Niaga, Politeknik Negeri Bali, Jl Kampus Bukit Jimbaran, \\ Kuta Selatan, Badung-Bali - 80364, Telp 0361-701981 (hunting) Fax 0361-701128
}

e-mail: mira.dwiastuti97@gmail.com

\begin{abstract}
ABSTRAK
Penelitian ini bertujuan untuk mengetahui implikasi Customer Relationship Marketing dan Digital Marketing terhadap kepuasan konsumen pada PT Gapura Angkasa JOUMPA Denpasar. Jumlah sampel yang digunakan sebanyak 68 orang. Data yang digunakan adalah data primer dan data sekunder dengan teknik pengambilan data menggunakan kuesioner. Data dianalisis secara deskriptif kuantitatif dengan SPSS 23.0

Hasil penelitian menunjukkan bahwa secara parsial sebesar 45,1\% Customer Relationship Marketing $\left(\mathrm{X}_{1)}\right.$ ber implikasi positif dan signifikan terhadap Kepuasan Konsumen (Y) dan sebesar 14\% Digital Marketing $\left(\mathrm{X}_{2}\right)$ berimplikasi positif dan signifikan terhadap Kepuasan Konsumen (Y). Secara simultan Customer Relationship Marketing $\left(\mathrm{X}_{1}\right)$ dan Digital Marketing $\left(\mathrm{X}_{2}\right)$ berimplikasi sebesar 59,1\% terhadap Kepuasan Konsumen (Y) dan 40,9\% karena adanya faktor-faktor lain di luar model penelitian.
\end{abstract}

Kata kunci: Customer Relationship Marketing, Digital Marketing; Kepuasan Konsumen.

\section{ABSTRACT}

This study aims to determine the implications of Customer Relationship Marketing and Digital Marketing for consumer satisfaction at PT Gapura Angkasa JOUMPA Denpasar. The number of samples used was 68 people. The data used are primary data and secondary data with data collection techniques using a questionnaire. Data were analyzed descriptively quantitatively with SPSS 23.0

The results showed that partially 45.1\% Customer Relationship Marketing (X1) had positive and significant implications for Consumer Satisfaction (Y) and 14\% Digital Marketing (X2) had positive and significant implications for Consumer Satisfaction (Y). Simultaneously Customer Relationship Marketing (X1) and Digital Marketing (X2) have 59.1\% implications for Consumer Satisfaction (Y) and 40.9\% due to other factors outside the research model.

Keywords: Customer Relationship Marketing, Digital Marketing; Customer Satisfaction.

\section{PENDAHULUAN}

\section{Latar Belakang}

Persaingan usaha di era globalisasi memungkinkan semakin ketat dan luasnya persaingan usaha diantara perusahaan-perusahaan, baik perusahaan pada bidang jasa, perdagangan maupun industri. Pemasaran memiliki peranan penting dalam membuat suatu perusahaan menjadi lebih kreatif sehingga dapat memberikan produk atau jasa yang sesuai dengan keinginan konsumen untuk mempertahankan kelangsungan hidup perusahaan itu sendiri. (Kotler \& Armstrong, 2017:28) pemasaran lebih dari fungsi bisnis lainnya, berhubungan dengan konsumen. Dua tujuan pemasaran adalah menarik konsumen baru dengan menjanjikan nilai superior untuk menjaga konsumen saat ini dengan memberikan nilai dan kepuasan.

Pemasaran di dalam organisasi atau perusahaan harus dikembangkan dengan pengelolaan yang baik agar seluruh fungsi-fungsi manajemen pemasaran dapat terwujud sehingga semua yang menjadi tujuan 
perusahaan bisa tercapai dengan optimal dan perusahaan terus berkembang sesuai dengan tuntutan persaingan kompetitif pada era globalisasi ini. Strategi yang dapat digunakan oleh perusahaan adalah Customer Relationship Marketing dan Digital Marketing.

Customer Relationship Marketing menurut (Semuel, 2012:33) adalah salah satu bentuk kualitas layanan yang diukur melalui komitmen, komunikasi, dan penanganan keluhan. Dalam arti yang luas Customer Relationship Marketing adalah keseluruhan proses membangun dan memelihara hubungan dengankonsumen yang menguntungkan serta menghantarkan nilai dan kepuasan konsumen. Pengukuran variabel Customer Relationship Marketing menurut(Budiman, 2016:12) yaitu Fokus konsumen jangka panjang, Membuat komunikasi dengan konsumen, Implementasi proses interaktif pemasaran, Mengembangkan budaya pelayanan untuk konsumen,Memperoleh dan menggunakan informasi konsumen.

Digital Marketing merupakan suatu sistem yang terkenal dalam dunia pemasaran saat ini. Di era digital, segala bentuk informasi dapat diakses dengan begitu cepat dan mudah melalui perangkat teknologi. Strategi Digital Marketing ini lebih prospektif karena memungkinkan para calon konsumen potensial untuk memperoleh berbagai informasi mengenai produk dan bertransaksi melalui internet. Revolusi tersebut menimbulkan pentingnya peran internet dalam kebutuhan masyarakat sehari-hari. Pengukuran Digital Marketingmenurut(Budiman, 2016:14) dapat dilakukan dengan indikatorWebsite, Jejaring Sosial, Emaildan Adwords.

Salah satu lingkungan usaha yang permintaan pasarnya selalu meningkat dari tahun ke tahun adalah industri transportasi. Transportasi merupakan kebutuhan yang sangat penting, seiring dengan meningkatnya pertumbuhan penduduk, pendapatan per-kapita, pendidikan, teknologi, dan komunikasi, serta berubahnya gaya hidup sosial manusia. Industri transportasi udara adalah salah satu industri paling maju saat ini. Hal ini disebabkan karena transportasi udara merupakan alat transportasi yang efektif, cepat, aman dan nyaman (Sakti, 2012:21).

Adanya peningkatan kebutuhan sarana transportasi tidak lepas dari keinginan masyarakat untuk mendapatkan sarana transportasi yang baik dengan keriteria aman, cepat, murah dan nyaman. Perubahan selera dalam pemilihan jenis sarana angkutan tidak lepas dari adanya perkembangan sosial ekonomi masyarakat serta kemajuan teknologi.

Sebagai perusahaan yang berbasis jasa, PT Gapura Angkasa harus mengutamakan pelayanan serta menggunakan strategi yang tepat demi kepuasan konsumennya. Kepuasan Konsumen menurut (Amaliyah \& Sunarti, 2018:12) adalah sebagai evaluasi pelanggan atas produk atau jasa. PT Gapura Angkasa merupakan perusahaan airport service. Salah satu unit yang dikelola oleh PT Gapura Angkasa adalah JOUMPA Airport VIP Service. JOUMPA merupakan layanan VIP yang memberikan kemudahan penumpang pesawat udara di bandara melalui beragam product seperti: Meet and Greet, Transfer, Fast Track,Baggage Delivery Servicedan lainnya di 60 Bandara di Indonesia. Untuk dapat terus menjadi perusahaan yang dapat bersaing di era digitalini JOUMPA sangat memerlukan strategi yang tepat dalam upaya untuk mendapatkan dan mempertahankan konsumennya. Menurut Philip Kotler untuk mengukur kepuasan konsumen dalam(Wardani, 2017:42) dapat dilakukan dengan mengukur indikator-indikator sepertiKesetiaan, Keluhan (complain) dan Partisipasi.

Jumlah konsumen JOUMPA Denpasar selalu mengalami peningkatan setiap tahunnya. Berikut data yang menunjukkan adanya peningkatan jumlah konsumen kontrak dan Go Show JOUMPA dari tahun 20152018.

Gambar 1. Data Peningkatan Jumlah Konsumen Kontrak JOUMPA Denpasar Tahun 2015-2018

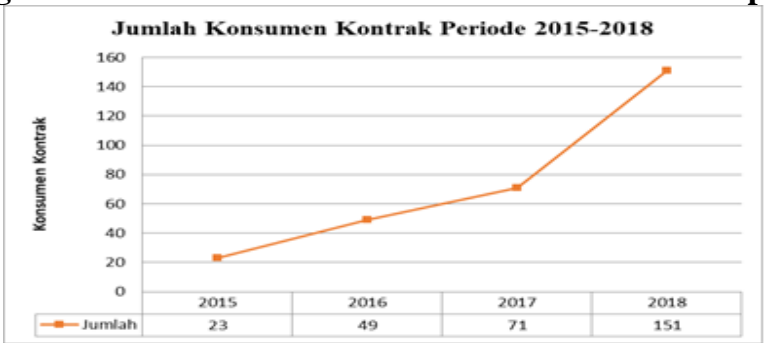

Sumber: Marketing JOUMPA Denpasar

Gambar tersebut di atas menunjukkan dari tahun ke tahun jumlah konsumen kontrak JOUMPA selalu meningkat. Pada tahun 2015 dengan jumlah 23, tahun 2016 dengan jumlah 49, tahun 2017 sebanyak 71 dan tahun 2018 berjumlah 151 company. 


\section{Gambar 2. Data Peningkatan Jumlah Konsumen Go Show JOUMPA Denpasar Tahun 2015-2018}

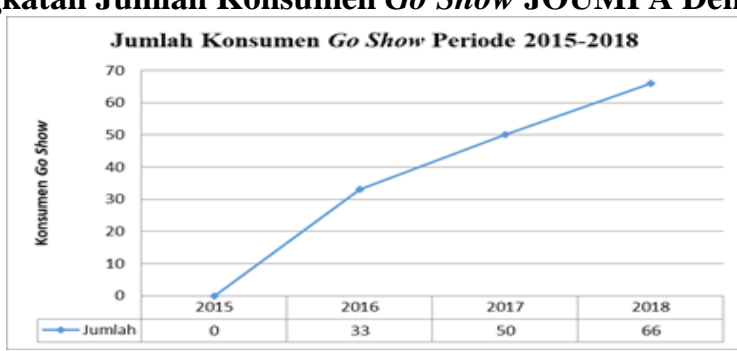

Sumber: Marketing JOUMPA Denpasar

Dapat dilihat pada gambar tersebut di atas dari tahun ke tahun jumlah konsumen Go Show JOUMPA selalu meningkat. Konsumen Go Show merupakan konsumen JOUMPA yang melakukan booking tanpa adanya kontrak atau perjanjian dengan sistem pembayaran pay cash. Jumlah konsumen pada tahun 2015 dengan jumlah 0, tahun 2016 dengan jumlah 33, tahun 2017 sebanyak 50 dan tahun 2018 berjumlah 66 yang melakukan booking layanan berulang kali tanpa sebuah kontrak.

Namun ternyata, dibalik peningkatan jumlah konsumen masih terdapat keluhan-keluhan dari konsumen seperti:

Tabel 1. Data Keluhan Konsumen pada PT Gapura Angkasa JOUMPA Denpasar

\begin{tabular}{lll}
\hline No & Jenis Keluhan & Bagian \\
\hline 1. & Konsumen tidak terjemput & Operasional \\
\hline 2. & Konsumen kehilangan bagasi & Operasional \\
\hline 3. & $\begin{array}{l}\text { Konsumen terlalu lama menunggu } \\
\text { penjemputan dari team JOUMPA }\end{array}$ & Operasional \\
& Terjadi miss komunikasi & Operasional \\
\hline S. & Sumber: JOUMPA Airport VIP Service. &
\end{tabular}

Dengan adanya keluhan-keluhan tersebut di atas, menunjukkan masih perlunya peningkatan dari segi kualitas pelayanan. Dengan strategi Customer Relationship Marketing diharapkan dapat memberikan solusi atas keluhan-keluhan yang biasa terjadi. Sehingga dengan penerapan Customer Relationship Marketing dan Digital Marketing yang baik, akan diharapkan juga tercapainya kepuasan konsumen PT Gapura Angkasa JOUMPA Airport VIP Service Cabang Denpasar Bali.

\section{Perumusan Masalah}

Berdasarkan di atas, dirumuskan suatu permasalahan adalah apakah penerapan Customer Relationship Marketing dan Digital Marketing mempunyai implikasi terhadap kepuasan konsumen pada PT Gapura Angkasa JOUMPA Denpasar".

\section{Tujuan Penelitian}

Adapun tujuan penelitian ini adalah sebagai berikut:

1. Untuk mengetahui secara parsial implikasi penerapan Customer Relationship Marketing dan Digital Marketing terhadap kepuasan konsumen pada PT Gapura Angkasa JOUMPA Denpasar".

2. Untuk mengetahui secara simultan implikasi penerapan Customer Relationship Marketing dan Digital Marketing terhadap kepuasan konsumen pada PT Gapura Angkasa JOUMPA Denpasar".

\section{METODE PENELITIAN}

\section{Jenis Penelitian}

Penelitian ini merupakan penelitian asosiatif kausal. penelitian asosiatif kausal adalah "penelitian yang bertujuan untuk menganalisis hubungan antara satu variabel dengan variable lainya atau bagaimana suatu variabel mempengaruhi variabel lain". 


\section{Populasi dan Penentuan Sampel}

Populasi dalam penelitian ini adalah semua konsumen dari JOUMPA Airport VIP Service. Karakterisitik populasi yang telah ditetapkan adalah orang yang pernah menggunakan layanan JOUMPA Airport VIP Service dan sudah memanfaatkan sarana digital sebelum akhirnya menggunakan layanan JOUMPA

Jumlah sampel dari penelitian ini adalah sejumlah 68 responden. Besarnya jumlah sampel ditentukan dengan program G-Power dengan tingkat keyakinan $80 \%$. Hal ini dikarenakan populasi dari sampel yang akan diteliti jumlahnya tidak terhingga karena konsumen dari JOUMPA Airport VIP Service tersebar luas di berbagai wilayah. Oleh karena itu penentuan jumlah sampel ditentukan dengan program G-Power dan dengan teknik non probability sampling metode convinience sampling (teknik penarikan sampel dengan pertimbangan kemudahan).

\section{Jenis dan Sumber Data}

Dalam penelitian ini diperlukan data primer, yaitu data yang diperoleh langsung dari responden, dan data sekunder data yang diperoleh tidak langsung, yaitu dari dokumen-dokumen perusahaan,jurnal dan bukubuku literatur Manajemen Pemasaran yang memberikan informasi tentang Customer Relationship Marketing dan Digital Marketing.

\section{Teknik pengumpulan Data}

Teknik pengumpulan data yang digunakan dalam penelitian ini adalah : wawacara berdasarkan atas daftar pertanyaan yang telah disiapkan terlebih dahulu, dimana kuesioner dalam penelitian ini terdiri dari tiga bagian yaitu bagian A yang berisi pernyataan pengesahan dari lembaga yang bersangkutan, bagian B berisi pernyataan tentang keterangan pribadi responden, sedangkan bagian $\mathrm{C}$ berisi pernyataan yang merupakan penjabaran dari Variabel Customer Relationship Marketing, Digital Marketing dan Kepuasan Konsumen dengan menggunakan skala dari 1 sampai dengan 5 (sangat tidak setuju - sangat setuju), observasi yaitu mengamati tentang permasalahan-permasalahan yang terjadi dan melihat terdapat beberapa upaya yang dilakukan perusahaan ini untuk meningkatkan Kepuasan Pelanggan dengan strategi pemasarannya yaitu dengan penerapan Customer Relationship Marketing dan Digital Marketing dan dokumentasi.

\section{Identifikasi Variabel}

1. Variabel terikat, yaitu variabel yang diimplikasikan oleh variabel lain. Variabel terikat dalam penelitian ini adalah Kepuasan Konsumen (Y).

2. Variabel bebas, yaitu variabel yang mengimplikasikan variabel yang lain. Variabel bebas dalam penelitian ini adalah Customer Relationship Marketing $\left(\mathrm{X}_{1}\right)$ dan Digital Marketing $\left(\mathrm{X}_{2}\right)$.

\section{Analisis Data}

Data dianalisis menggunakan Regresi Linear Berganda menurut formulasi Sugiyono (2010: 277) :

$$
\mathrm{Y}=\mathbf{a}+\boldsymbol{b} 1 X 1+b 2 X 2
$$

Keterangan:

Y : Variabel terikat, yaitu Kepuasan Konsumen

a : Konstanta yang merupakan rata-rata nilai Y pada saat nilai $X_{1}$ dan $X_{2}$ sama dengan nol

$X_{1}$ : Variabel bebas, Customer Relationship Marketing

$X_{2}$ : Variabel bebas, Digital Marketing

$b 1$ : Koefisien regresi parsial, mengukur rata-rata nilai Y untuk tiap perubahan $X_{1}$ dengan menganggap $X_{2}$ konstan.

$b 2$ : Koefisien regresi parsial, mengukur rata-rata nilai $\mathrm{Y}$ untuk tiap perubahan $X_{2}$ dengan menganggap $X_{1}$ konstan. 


\section{HASIL DAN PEMBAHASAN}

\section{Analisis Data Statistik Deskriptif}

1) Variabel Customer Relationship Marketing $\left(\mathrm{X}_{1}\right)$

Tabel 2. Distribusi Kuesioner Customer Relationship Marketing $\left(\mathrm{X}_{1}\right)$

\begin{tabular}{|c|c|c|c|}
\hline Pernyataan & Total Skor & Rata-rata & Dimensi \\
\hline CR1 & 247 & 3,63 & \multirow{5}{*}{$\begin{array}{c}\text { Fokus konsumen jangka Panjang. } \\
\text { Rata-rata Skor } \mathbf{3 , 5 8}\end{array}$} \\
\hline CR2 & 240 & 3,52 & \\
\hline CR3 & 249 & 3,66 & \\
\hline CR4 & 246 & 3,61 & \\
\hline CR5 & 240 & 3,52 & \\
\hline CR6 & 242 & 3,55 & \multirow{4}{*}{$\begin{array}{l}\text { Membuat komunikasi dengan } \\
\text { konsumen. Rata-rata skor } \mathbf{3 , 6 3}\end{array}$} \\
\hline CR7 & 248 & 3,64 & \\
\hline CR8 & 245 & 3,60 & \\
\hline CR9 & 255 & 3,75 & \\
\hline CR10 & 242 & 3,55 & \multirow{5}{*}{$\begin{array}{l}\text { Implementasi proses interaktif } \\
\text { pemasaran. Rata-rata skor } \mathbf{3 , 6 8}\end{array}$} \\
\hline CR11 & 251 & 3,69 & \\
\hline CR12 & 246 & 3,61 & \\
\hline CR13 & 249 & 3,66 & \\
\hline CR14 & 267 & 3,92 & \\
\hline CR15 & 245 & 3,60 & \multirow{3}{*}{$\begin{array}{l}\text { Mengembangkan budaya } \\
\text { pelayanan untuk konsumen. } \\
\text { Rata-rata skor } \mathbf{3 , 6 3}\end{array}$} \\
\hline CR16 & 249 & 3,66 & \\
\hline CR17 & 248 & 3,64 & \\
\hline CR18 & 255 & 3,75 & \multirow{2}{*}{$\begin{array}{l}\text { Memperoleh dan menggunakan } \\
\text { informasi konsumen. Rata-rata skor } \\
\mathbf{3 , 6 4}\end{array}$} \\
\hline CR19 & 248 & 3,64 & \\
\hline $\begin{array}{l}\text { Rata-rata } \\
\text { Relationship I } \\
\end{array}$ & $\begin{array}{l}\text { Skor Customer } \\
\text { Marketing }\left(\mathrm{X}_{1}\right)\end{array}$ & 3,64 & \\
\hline
\end{tabular}

Dalam penelitian ini ditentukan bahwa skor rata-rata untuk 1 item pernyataan $<3,5$ diartikan bahwa responden kurang setuju dan > 3,5 responden menyatakan setuju dengan item pernyataan kuesioner. Berdasarkan tabel 4.4 distribusi kuesioner Customer Relationship Marketing yang terdiri atas 19 item pernyataan menunjukkan total rata-rata skor sebesar 3,64.

Untuk dimensi Fokus Konsumen Jangka Panjang diperoleh rata-rata skor sebesar 3,58; Membuat komunikasi dengan konsumen sebesar 3,63; Implementasi proses interaktif pemasaran sebesar 3,68; Mengembangkan budaya pelayanan untuk konsumen sebesar 3,63; Memperoleh dan menggunakan informasi konsumen sebesar 3,64 yang menunjukkan bahwa secara rata-rata responden menyatakan setuju dengan semua item dalam dimensi Customer Relationship Marketing karena hasil rata-rata skor menunjukkan skor > 3,5 .

2) Variabel Digital Marketing $\left(\mathrm{X}_{2}\right)$

Tabel 3. Distribusi Kuesioner Digital Marketing $\left(\mathrm{X}_{2}\right)$

\begin{tabular}{|c|c|c|c|}
\hline Pernyataan & Total Skor & Rata-rata & Dimensi \\
\hline DM1 & 245 & 3,6 & Website \\
\hline DM2 & 265 & 3,89 & Rata-rata skor 3,63 \\
\hline DM3 & 213 & 3,13 & \\
\hline DM4 & 248 & 3,64 & \\
\hline DM5 & 265 & 3,89 & \\
\hline DM6 & 262 & 3,85 & Jejaring Sosial \\
\hline DM7 & 272 & 4 & Rata-rata skor 3,91 \\
\hline DM8 & 270 & 3,97 & \\
\hline DM9 & 272 & 4 & \\
\hline DM10 & 270 & 3,77 & \\
\hline DM11 & 257 & 3,97 & E-mail \\
\hline DM12 & 270 & 3,52 & Rata-rata skor $\mathbf{3 , 7 7}$ \\
\hline DM13 & 238 & 3,70 & \\
\hline DM14 & 252 & 3,72 & \\
\hline DM15 & 253 & 3,94 & \\
\hline DM16 & 268 & 3,94 & Adwords \\
\hline DM17 & 249 & 3,66 & Rata-rata skor $\mathbf{3 , 7 2}$ \\
\hline DM18 & 250 & 3,67 & \\
\hline DM19 & 253 & 3,72 & \\
\hline DM20 & 247 & 3,63 & \\
\hline $\begin{array}{l}\text { Rata-rata Skor } \\
\text { Marketing }\left(\mathbf{X}_{1}\right)\end{array}$ & Customer Relationship & 3,76 & \\
\hline
\end{tabular}

Sumber: Data primer diolah,2019. 
Berdasarkan Tabel 3. di atas distribusi kuesioner Digital Marketing yang terdiri atas 20 item pernyataan menunjukkan total rata-rata skor sebesar 3,76. Untuk dimensi Website diperoleh rata-rata skor sebesar 3,63; Jejaring sosial sebesar 3,91; E-mail sebesar 3,77 dan Adwords sebesar 3,72 yang menunjukkan bahwa secara rata-rata responden menyatakan setuju dengan semua item dalam dimensi Digital Marketing karena hasil rata-rata skor menunjukkan > 3,5. Namun pada item pernyataan DM3 yaitu Pemesanan layanan (booking) melalui website membantu meng-efisienkan waktu berada pada nilai rata-rata skor < 3,5 yaitu dengan perolehan skor sebesar 3,13 yang artinya bahwa responden kurang setuju dengan pernyataan kuesioner tersebut.

3) Variabel Kepuasan Konsumen (Y)

Tabel 4. Distribusi Kuesioner Kepuasan Konsumen (Y)

\begin{tabular}{|c|c|c|c|}
\hline Pernyataan & Total Skor & Rata-rata & Dimensi \\
\hline KK1 & 249 & 3,66 & \multirow{5}{*}{$\begin{array}{c}\text { Kesetiaan } \\
\text { Rata-rata skor } \\
\mathbf{3 , 5 9}\end{array}$} \\
\hline KK2 & 238 & 3,52 & \\
\hline KK3 & 252 & 3,7 & \\
\hline KK4 & 253 & 3,72 & \\
\hline KK5 & 253 & 3,72 & \\
\hline KK6 & 249 & 3,66 & \multirow{5}{*}{$\begin{array}{c}\text { Keluhan } \\
\text { Rata-rata skor } \\
\mathbf{3 , 6 7}\end{array}$} \\
\hline KK7 & 249 & 3,66 & \\
\hline KK8 & 240 & 3,54 & \\
\hline KK9 & 2,65 & 3,89 & \\
\hline KK10 & 248 & 3,64 & \\
\hline KK11 & 251 & 3,69 & \multirow{4}{*}{$\begin{array}{c}\text { Partisipasi } \\
\text { Rata-rata skor } \\
\mathbf{3 , 6 6}\end{array}$} \\
\hline KK12 & 245 & 3,6 & \\
\hline KK13 & 247 & 3,63 & \\
\hline KK14 & 253 & 3,72 & \\
\hline $\begin{array}{l}\text { Rata-rata Skor } \\
\text { Marketing }\left(\mathrm{X}_{1}\right) \\
\end{array}$ & Customer Relationship & 3,66 & \\
\hline
\end{tabular}

Berdasarkan Tabel 4 di atas distribusi kuesioner Kepuasan Konsumen yang terdiri atas 14 item pernyataan menunjukkan total rata-rata skor sebesar 3,66.Untuk dimensi Kesetiaan diperoleh rata-rata skor sebesar 3,59; Keluhan sebesar 3,67; dan Partisipasi sebesar 3,66 yang menunjukkan bahwa secara rata-rata responden menyatakan setuju dengan semua item dalam dimensi Kepuasan Konsumen karena hasil rata-rata skor menunjukkan > 3,5.

\section{Analisis Regresi Linier Berganda}

Menurut Iqbal (2014:107) Analisis Regresi Linier Berganda digunakan untuk menguji signifikan atau tidaknya hubungan antara dua atau lebih variabel melalui koefisien regresinya serta untuk mengetahui implikasi antara variabel terikat dengan variabel bebas. Berdasarkan pengujian dengan bantuan program SPSS for Windows 23.0 diperoleh hasil yang dapat disajikan dalam tabel berikut.

Tabel 5. Hasil Uji Regresi Linier Berganda Variabel Customer Relationship Marketing, Digital Marketing Dan Kepuasan Konsumen

\begin{tabular}{|c|c|c|c|c|c|}
\hline \multirow[t]{2}{*}{ Model } & \multicolumn{2}{|c|}{$\begin{array}{c}\text { Unstandardized } \\
\text { Coefficients }\end{array}$} & \multirow{2}{*}{$\begin{array}{c}\begin{array}{c}\text { Standardized } \\
\text { Coefficients }\end{array} \\
\text { Beta } \\
\end{array}$} & \multirow[t]{2}{*}{$\mathbf{t}$} & \multirow[t]{2}{*}{ Sig. } \\
\hline & B & Std. Error & & & \\
\hline $\begin{array}{l}\text { (Constant) } \\
\text { Customer } \\
\text { Relationship } \\
\text { Marketing } \\
\text { Digital Marketing }\end{array}$ & $\begin{array}{c}14,352 \\
0,247 \\
0,285\end{array}$ & $\begin{array}{l}3,970 \\
0,052 \\
0,057\end{array}$ & $\begin{array}{l}0,431 \\
0,459\end{array}$ & $\begin{array}{l}3,615 \\
4,732 \\
5,044\end{array}$ & $\begin{array}{l}0,001 \\
0,000 \\
0,000\end{array}$ \\
\hline $\begin{array}{l}\mathrm{R} \\
\mathrm{R} \text { Square } \\
\text { F hitung } \\
\text { Sig. F }\end{array}$ & & & & & $\begin{array}{c}0,769 \\
0,591 \\
47,033 \\
0,000 \\
\end{array}$ \\
\hline
\end{tabular}

Sumber: Data primer diolah,2019. 
Berdasarkan hasil analisis regresi linier berganda seperti yang disajikan tabel 5 diatas, maka persamaan strukturalnya adalah sebagai berikut.

$$
\begin{aligned}
& \mathrm{Y}=\mathrm{a}+\boldsymbol{b}_{1} \boldsymbol{X}_{\mathbf{1}}+\boldsymbol{b}_{2} \boldsymbol{X}_{\mathbf{2}} \\
& \mathrm{Y}=14,352+0,247 \mathrm{X}_{1}+0,285 \mathrm{X}_{2}
\end{aligned}
$$

1. $\mathrm{a}=14,352$ artinya apabila Customer Relationship Marketing $\left(\mathrm{X}_{1}\right)$ dan Digital Marketing $\left(\mathrm{X}_{2}\right)$ nilainya adalah 0, maka Kepuasan Konsumen (Y) adalah sebesar 14,352

2. $\mathrm{b}_{1}=0,247$, artinya apabila Digital Marketing $\left(\mathrm{X}_{2}\right)$ diasumsikan tidak ada, maka meningkatnya Customer Relationship Marketing $\left(\mathrm{X}_{1}\right)$ sebesar satu satuan akan diikuti oleh meningkatnya Kepuasan Konsumen (Y) sebesar 0,247.

3. Sedangkan $\mathrm{b}_{2}=0,285$, artinya apabila Customer Relationship Marketing $\left(\mathrm{X}_{1}\right)$ diasumsikan tidak ada, maka meningkatnya Digital Marketing $\left(\mathrm{X}_{2}\right)$ sebesar satu satuan akan diikuti oleh meningkatnya Kepuasan Konsumen (Y) sebesar 0,285.

\section{Uji Parsial (Uji T)}

Kriteria pengujian untuk menjelaskan interpretasi implikasi antar masing-masing variabel adalah sebagai berikut.

Jika Sig. $\mathrm{t}<0.05$ maka $\mathrm{H}_{0}$ ditolak dan $\mathrm{H}_{1}$ diterima.

Jika Sig. $\mathrm{t}>0.05$ maka $\mathrm{H}_{0}$ diterima dan $\mathrm{H}_{1}$ ditolak.

1. Implikasi Customer Relationship Marketing terhadap Kepuasan Konsumen.

Berdasarkan hasil pada tabel 5 di atas, diketahui bahwa variabel Customer Relationship Marketing memiliki nilai Sig. $t$ sebesar 0,000 dengan $t_{\text {hitung }} 4,732$. Nilai Sig. t 0,000 $<0,05$ mengindikasikan bahwa Customer Relationship Marketing berimplikasi positif dan signifikan terhadap Kepuasan Konsumen.

2. Implikasi Digital Marketing terhadap Kepuasan Konsumen

Berdasarkan tabel 5 di atas, diketahui bahwa variabel Digital Marketing memiliki nilai Sig. t sebesar 0,000 dengan nilai t hitung sebesar 5,044. Nilai sig. t 0,000<0,05 mengindikasikan bahwa Digital Marketing berimplikasi positif dan signifikan terhadap Kepuasan Konsumen.

\section{Uji Simultan (F)}

Uji F dilakukan dengan melihat nilai signifikansi pada tabel anova dengan bantuan program SPSS23.0 for windows. Bila nilai sig. $\left\langle\alpha(\alpha=0.05)\right.$ atau $F_{\text {hitung }}>F_{\text {tabel }}$ maka model ini dikatakan layak atau variabel bebas mampu menjelaskan variabel terikat.

Tabel 6. HASIL UJI F (ANOVA) ANOVA $^{\mathrm{a}}$

\begin{tabular}{|ll|r|r|r|r|r|}
\hline Model & Sum of Squares & Df & Mean Square & F & Sig. \\
\hline 1 & Regression & 534.481 & 2 & 267.241 & 47.033 & $.000^{\mathrm{b}}$ \\
& Residual & 369.328 & 65 & 5.682 & & \\
& Total & 903.809 & 67 & & & \\
\hline
\end{tabular}

Sumber:Data diolah, 2019.

a. Dependent Variable: KK

b. Predictors: (Constant), DM, CRM

Berdasarkan Tabel 6 hasil uji anova di atas, didapat nilai F hitung 47.033yang lebih besar dari 3,13 (F tabel) dan nilai sig. F adalah sebesar 0,000 yang lebih kecil dari 0,05 (sig. $<\alpha$ ). Hal ini berarti variabel bebas yaitu Customer Relationship Marketing $\left(\mathrm{X}_{1}\right)$ dan Digital Marketing $\left(\mathrm{X}_{2}\right)$ berimplikasi positif dan signifikan secara simultan terhadap variabel terikat yaitu Kepuasan Konsumen (Y).

\section{Koefisien Determinasi Simultan}

Berdasarkan Tabel 2 diatas,dapat dilihat bahwa besarnya nilai $\mathrm{R}$ square adalah sebesar 0,591 yang artinya sebesar 59,1\% variabel Kepuasan Konsumen diimplikasikan oleh Customer Relationship Marketing dan Digital Marketing, sedangkan sisanya sebesar 40,9\% diimplikasikan oleh faktor-faktor lain yang tidak dimasukkan ke dalam model penelitian. 


\section{Koefisien Determinasi Parsial}

Tabel 7. Koefisien Determinasi

Model Summary

\begin{tabular}{|c|c|c|c|c|c|c|c|c|c|}
\hline \multirow[b]{2}{*}{ Model } & \multirow[b]{2}{*}{$\mathrm{R}$} & \multirow[b]{2}{*}{$\begin{array}{c}\mathrm{R} \\
\text { Square }\end{array}$} & \multirow[b]{2}{*}{$\begin{array}{l}\text { Adjusted R } \\
\text { Square }\end{array}$} & \multirow[b]{2}{*}{$\begin{array}{l}\text { Std. Error of the } \\
\text { Estimate }\end{array}$} & \multicolumn{5}{|c|}{ Change Statistics } \\
\hline & & & & & $\begin{array}{l}\text { R Square } \\
\text { Change }\end{array}$ & $\begin{array}{c}\mathrm{F} \\
\text { Change }\end{array}$ & df1 & df2 & $\begin{array}{c}\text { Sig. F } \\
\text { Change }\end{array}$ \\
\hline $\begin{array}{l}1 \\
2\end{array}$ & $\begin{array}{l}.671^{\mathrm{a}} \\
.769^{\mathrm{b}}\end{array}$ & $\begin{array}{l}.451 \\
.590\end{array}$ & $\begin{array}{l}.442 \\
.579\end{array}$ & $\begin{array}{l}2.743 \\
2.384\end{array}$ & $\begin{array}{l}.451 \\
.140\end{array}$ & $\begin{array}{l}54.129 \\
22.393\end{array}$ & $\begin{array}{l}1 \\
1\end{array}$ & $\begin{array}{l}66 \\
65\end{array}$ & $\begin{array}{l}.000 \\
.000\end{array}$ \\
\hline
\end{tabular}

Sumber: Data diolah, 2019.

a. Predictors: (Constant), DM

b. Predictors: (Constant), DM, CRM

Berdasarkan pada Tabel 7 di atas, dapat dilihat bahwa nilai $R$ Square Change untuk variabel Customer Relationship Marketing $\left(\mathrm{X}_{1}\right)$ memberikan implikasi sebesar 45,1\% terhadap variabel Kepuasan Konsumen (Y). Sedangkan variabel Digital Marketing $\left(\mathrm{X}_{2}\right)$ memberikan implikasi sebesar $14 \%$ terhadap variabel Kepuasan Konsumen (Y) dengan masing-masing Sig. F Change adalah 0,000. Sehingga dari implikasi simultan sejumlah 59,1\% tersebut Customer Relationship Marketing $\left(\mathrm{X}_{1}\right)$ memberi implikasi sebesar 45,1\% dan Digital Marketing $\left(\mathrm{X}_{2}\right)$ sebesar 14\%.

\section{Implikasi Customer Relationship Marketing $\left(\mathrm{X}_{1}\right)$ terhadap Kepuasan Konsumen(Y)}

Hasil penelitian menunjukkan bahwa $\mathrm{H}_{1}$ diterima yaitu Customer Relationship Marketing $\left(\mathrm{X}_{1}\right)$ berimplikasi positif dan signifikan terhadap Kepuasan Konsumen (Y). Hal ini dapat dilihat dari tabel 5. dimana nilai signifikansi yang diperoleh adalah 0,000 yang lebih kecil dari 0,05. Sehingga ini berarti apabila Customer Relationship Marketing $\left(\mathrm{X}_{1}\right)$ meningkat maka Kepuasan Konsumen (Y) pun meningkat. Sedangkan sebaliknya apabila Customer Relationship Marketing menurun maka Kepuasan Konsumen juga menurun. Selain itu, jika dilihat dari tabel 7. diperoleh koefisien determinasi parsial sebesar 0,451 yang berarti variabel Kepuasan Konsumen diimplikasikan sebesar 45,1\% oleh Customer Relationship Marketing $\left(\mathrm{X}_{1}\right)$. Hasil ini juga didukung oleh hasil penelitian sebelumnya oleh Alwin Fauzi Hermawan (2018:200) yang memperoleh bahwa Customer Relationship Marketing $\left(\mathrm{X}_{1}\right)$ berimplikasi signifikan terhadap variabel Kepuasan Konsumen (Y).

2. Implikasi Digital Marketing $\left(\mathrm{X}_{2}\right)$ terhadap Kepuasan Konsumen (Y)

Hasil penelitian menunjukkan bahwa $\mathrm{H} 1$ diterima yaitu Digital Marketing $\left(\mathrm{X}_{2}\right)$ berimplikasi positif dan signifikan terhadap Kepuasan Konsumen (Y). Hal ini dapat dilihat dari tabel 5. dimana nilai signifikansi yang diperoleh adalah 0,000 yang lebih kecil dari 0,05. Sehingga ini berarti apabila Digital Marketing $\left(\mathrm{X}_{2}\right)$ meningkat maka Kepuasan Konsumen (Y) pun meningkat. Sedangkan sebaliknya apabila Digital Marketing menurun maka Kepuasan Konsumen juga menurun. Selain itu, jika dilihat dari tabel 7. diperoleh koefisien determinasi parsial sebesar 0,140 yang berarti variabel Kepuasan Konsumendiimplikasikan sebesar $14 \%$ oleh Digital Marketing $\left(\mathrm{X}_{2}\right)$.

3. ImplikasiCustomer Relationship Marketing $\left(\mathrm{X}_{1}\right)$ dan Digital Marketing $\left(\mathrm{X}_{2}\right)$ berimplikasi secara simultan terhadap Kepuasan Konsumen (Y) . Hasil penelitian menunjukkan bahwa H1 diterima yaitu Customer Relationship Marketing $\left(\mathrm{X}_{1}\right)$ dan Digital Marketing $\left(\mathrm{X}_{2}\right)$ berimplikasi secara simultan terhadap Kepuasan Konsumen (Y). Hal ini dapat dilihat dari tabel 6. dimana nilai signifikansi yang diperoleh adalah 0,000 yang lebih kecil dari 0,05 serta diperoleh $F_{\text {hitung }}$ sebesar 47.033lebih besar dari $F_{\text {tabel }}$ sebesar 3,13. Selain itu, jika dilihat dari tabel 5. diperoleh koefisien determinasi simultan sebesar 0,591 yang berarti variabel Kepuasan Konsumen diimplikasikan sebesar 59,1\% oleh Customer Relationship Marketing ( $\left.\mathrm{X}_{1}\right)$ dan Digital Marketing $\left(\mathrm{X}_{2}\right)$ dan sisanya sebesar 40,9\% diimplikasii oleh faktor-faktor lain yang tidak dimasukkan ke dalam model penelitian.

\section{SIMPULAN DAN SARAN}

\section{Simpulan}

Hasil analisis data menyatakan secara parsial maupun secara simultan berimplikasi positif dan signifikan terhadap Kepuasan Konsumen yaitu (1) Customer Relationship Marketing sebesar 45,1 persen dan nilai t sebesar 4.732 dengan nilai sig $0,000<$ alpha 0,05 (2) Digital Marketing sebesar 14 persen dan nilai t sebesar 5.044 dengan nilai sig 0,000 < alpha 0,05 (3) Customer Relationship Marketing dan Digital Marketing sebesar 59,1 persen nilai F sebesar 47.033 dengan nilai sig 0,000 < alpha 0,05. 


\section{Saran}

1. Dilihat dari variabel $\mathrm{X}_{1}$ (Customer Relationship Marketing), indikator yang memiliki nilai rata-rata skor terendah yaitu Fokus Konsumen Jangka Panjang dengan total rata-rata skor sebesar 3,58 dan rata-rata skor terendah sebesar 3,52 pada pernyataan "JOUMPA merupakan layanan VIP yang selalu bisa diandalkan". sehingga hal tersebut mengacu pada permasalahan yang terjadi berdasarkan observasi penulis seperti konsumen tidak terjemput, konsumen kehilangan bagasi, konsumen terlalu lama menunggu penjemputan dari team JOUMPA dan terjadinya miss komunikasi. Permasalahanpermasalahan tesebut hendaknya diantisipasi dengan melakukan evaluasi dan melakukan pelatihan terhadap karyawan serta pembagian tugas sesuai dengan kemampuan karyawan sehingga tidak terjadi kesalahan dalam proses pelayanan. Tetapi secara keseluruhan, item dari pernyataan masih pada rentang setuju karena ada pada skor>3,5.

2. Dari variabel $\mathrm{X}_{2}$ (Digital Marketing), indikator yang memiliki nilai total skor rata-rata terendah yaitu Website dengan total rata-rata skor sebesar 3,63 dan perolehan nilai rata-rata skor terendah sebesar 3,13 pada item pernyataan "Pemesanan layanan (booking) melalui website membantu meng-efisienkan waktu". Hal ini menunjukkan bahwa perlu adanya peningkatan ataupun pembaharuan dalam sistem booking melalui website. Dengan melihat nilai rata-rata skor dibawah 3,5 menunjukkan bahwa pernyataan tersebut dalam rentang tidak setuju sehingga sangat perlu untuk ditingkatkan dan menjadi perhatian PT Gapura Angkasa JOUMPA Denpasar.Tetapisecarakeseluruhan, item dari pernyataan masih pada rentang setuju karena ada pada askor $>3,5$.

3. Dari variabel Y (Kepuasan Konsumen), indikator yang memiliki nilai terlemah adalah Kesetiaan dengan nilai total rata-rata skorsebesar 3,59 dan nilai rata-rata skor terendah sebesar 3,52 pada item pernyataan "Saya membutuhkan JOUMPA Airport VIP Service ketika saya bepergian dengan pesawat terbang". Perusahaan hendaknya dapat lebih meningkatkan dalam strategi pemasarannya seperti Customer Relationship Marketing danDigital Marketing hingga menciptakan customer retention (ingatan konsumen) bahwa“'Ingat Travelling, Ingat JOUMPA Denpasar". Tetapi secara keseluruhan, item dari pernyataan masih pada rentang setuju karena ada pada skor $>3,5$.

4. Bagi peneliti selanjutnya, dapat dimanfaatkan sebagai referensi dalam melakukan penelitian yang berhubungan dengan implikasiCustomer Relationship Marketing dan Digital Marketing terhadap Kepuasan Konsumen dengan mengembangkan variabel yang lebih luas dan bisa menambahkan variabelvariabel lainnya.

\section{DAFTAR PUSTAKA}

Amaliyah, Nur Putri dan Sunarti. 2018. "Analisis Relationship Marketing Terhadap Kepuasan Pelanggan Dan Dampaknya Pada Loyalitas Pelanggan.” Jurnal Administrasi Bisnis 55(1): 222-28.

Budiman, Novayanti. 2016. "Implikasi Digital Marketing Dan Customer Relationship Marketing Terhadap Loyalitas Konsumen Maskapai Penerbangan Garuda Indonesia." Manajemen Fakultas Ekonomi Dan Bisnis Universitas Hasanuddin Makassar.

Hermawan, A. F. (n.d.). 2018.Implikasi Customer Relationship Marketing Terhadap Kepuasan Dan Loyalitas Pelanggan ( Survei Pada Pelanggan Maskapai Penerbangan Garuda Indonesia Di Kota Malang ). 55(2), 192-201.

Kotler, Philip, and Gary Armstrong. 2017. Kotler_and_Armstrong_-_Principles_of_Mar.

Noor, Julianyah. 2011. Metodologi Penelitian. Pranada Media Group. Jakarta.

Sakti, Adji. 2012. "Penerbangan Dan Bandar Udara / Sakti Adji Adisasmita." In Yogyakarta: Graha Ilmu, 182. http://library.um.ac.id.

Sugiyono. 2010. Metode Penelitian Kuantitatif, Kualitatif Dan R \& D. Alfabeta. Bandung

Wardani, Tri Ulfa. 2017. Implikasi Kulaitas Pelayanan Terhadap Kepuasan Konsumen Pada Bisnis Transportasi Gojek. 